\title{
Research on the Benefits Allocation System of the Collaborative Innovation Center of China
}

\author{
Duanyang Ren1,2, Wei Song1,2, Guofeng Zhang1,2 \\ ${ }^{1}$ School of Public Affairs, University of Science and Technology of China, Hefei, China \\ ${ }^{2}$ Intellectual Property Office of Anhui Province, Hefei, China \\ Email: rdy@mail.ustc.edu.cn
}

Received 22 April 2015; accepted 20 June 2015; published 23 June 2015

Copyright (C) 2015 by authors and Scientific Research Publishing Inc.

This work is licensed under the Creative Commons Attribution International License (CC BY). http://creativecommons.org/licenses/by/4.0/

(c) (i) Open Access

\begin{abstract}
Collaborative innovation is a very important way for major scientific innovation; the core is adding knowledge value, involving firms, government, research institutions and other organizations. Collaborative innovation centers are important carriers for responding to the call of government's collaborative strategy. However, during the collaborative process, the problem of intellectual property ownership and benefits allocation is faced by cooperative parties. So, we try to solve the benefits allocation problem by constructing a reasonable mechanism. It is the basis for the steady operation of collaborative innovation center and benefits distribution fairly. This paper constructs a model for benefits allocation after we review previous studies. It includes intellectual property participating and sharing, benefits allocation and performance evaluation and feedback. Besides, we use a case study to examine this model. Thus, we hope this model can help keep the stable development of collaborative innovation center and has certain significance in theoretical implications.
\end{abstract}

\section{Keywords}

Collaborative Innovation, Intellectual Property, Benefits Allocation Mechanism

\section{Introduction}

As the rapid development of technology, technological innovation has become an important way to enhance innovation capability and promote the economic development of country. In this situation, the organization can't rely on itself to complete innovation activities, so that it has to turn to other organizations for collaboration. 
Thus, collaborative innovation is becoming a new innovation model and being popular. The collaborative parties include universities, companies, research institutions and government; these organizations have different purposes and needs. Collaborative innovation has to satisfy these different needs, and make different elements and benefits integrated, to gain " $1+1>2$ " effect. Also, collaborative innovation is a community of interests; reasonable benefits allocation mechanism can ensure the collaborative parties to gain integrated effect, besides the intellectual property, such as patent, the main content of R \& D results. So, it is necessary to design a reasonable, scientific and effective intellectual property (IP) benefits mechanism to guarantee the collaborative innovation activities [1]. IP benefits allocation mechanism can balance the rights and interests. It is necessary to understand the constitution of IP interests, as the premise of allocation benefits reasonably. The interests related IP includes ownership, licensing, transfer and usufruct. Different collaborative model has different benefits constitution of IP. Because the collaborative parties are multiple, they have different needs and purposes. It is important to deal with the IP to maintain the collaborative system. It has to meet different demands, and protect IP rights in case of the interests' conflict.

Some developed countries have explored relatively sound collaborative models and IP benefits allocation mechanisms, and have applied them in practice. Compared with these countries, our research on this issue started late, focusing on IP protection in recent years. In this development stage, our country encourages collaborative innovation strategy, and a batch of collaborative innovation centers has been built. Although the government makes policy to support this strategy, the reasonable mechanisms of participating or allocating benefits also are needed [2]. Domestic scholars explore the collaborative innovation on theoretical level, such as policy supporting or regulations publishing. Thus, this paper is based on related theory and investigation to explore IP benefits allocation mechanisms of collaborative innovation centers, and put forward some advice for collaborative innovation development.

\section{Research Object and Methodology}

\subsection{Research Object}

We investigate some collaborative innovation centers to collect some data of IP benefits allocation mechanisms. Based on these data, we construct general IP benefits allocation mechanisms and other supplementary mechanisms to ensure the benefits allocation fairly.

\subsection{Methodology}

\subsubsection{Literature Review}

We access to a large number of literature research to realize this field and use related theory as the basis for our research. We collect data and files from library database and some departments of collaborative innovation centers, which ensure the reliability of the evidences.

\subsubsection{Interviews}

We investigate some collaborative innovation centers and interview the staff who work in these centers, the researchers and manage members, so that we realize the situation of collaborative innovation centers and the needs of different people. During the interview, the researchers set formal and informal situations, and at least two people interviewed related staff once, one could ask questions and the other recorded the conversation. The interview outline covers many questions, such as "do you think you have significant contribution to the invention or patent?" "are you satisfied with the compensation or rewards you got?" "do you think the benefits allocation way is reasonable?" the interview data shows that the project leader and core researchers are satisfied with the rewards, but other research worker are not, because they also undertake a lot of work, but only get a little more overtime allowance and other rewards, these are not equal to they expected. Besides, if the patent was given to firms, the researchers are not only asking for rewards, they would also request the rights of patent commercial benefits. So we use these data to find out the problems in the existing benefits mechanisms and put forward some advice for implementation of benefit allocation.

\subsubsection{Systematic Analysis}

Innovation system is a sophisticated technologic-economic system, thus it determines the collaborative innovation model, as an important carrier of innovation ability, also has the systematic characteristic. To fully under- 
stand the collaborative innovation, we have to use systematic analysis to realize the relationship of different elements, thus it provides the basis for understand subsystem deeply. We construct a general model to describe IP benefits allocation mechanism and some supplementary mechanisms to ensure the allocation process fairly. It is helpful to use this method to explore synergic network of subsystems, so that the whole model can gain better effects.

\subsubsection{Case Study}

Case study can be used when the theory is new and little research conclusions on it as well as the regression analysis not suitable for the situation. Case study can examine theory model and draw new conclusions. We choose a typical collaborative innovation center as the case study object, to examine whether the theory model match the case or not. Thus we can conclude that the importance of collaborative mechanisms for collaborative innovation center and how to allocate the benefits fairly.

\section{Collaborative Innovation and Intellectual Property Benefits Allocation}

Collaborative innovation was defined by Gloor (2006), as "self-motivated staff formed collective visions, exchanging ideas, information and working condition to achieve common goals" [3]. The concept was extended later, to describe two or more organizations collaborate with others involving knowledge share and technology transfer, besides the collaborative parties including university, firms and research institution, also the collaborative mechanisms including participating, sharing and allocating. Compared with traditional innovation, collaborative innovation system is changing constantly. The elements in collaborative innovation are not added simply, but reacting to the changing environment [4].

Some domestic scholars regard collaborative innovation as industry-university-research cooperation (EUR cooperation), but our research regard collaborative innovation as a more complex way of innovation. The collaborative organizations not only including university, government, and research institutions, but also cooperative with financial agent and other service organization. It could integrate knowledge creation and technology application, forming a completely new innovation system. Organizations choose collaborative partners depends on the real needs not spontaneously. If lacking of the guidance of government, the result would be zero-sum game, individuals would prefer self-benefits maximum, which would have negative effect on group benefits. Thus, the purpose of collaborative innovation is not only achieving economic profits, but also to gain technological breakthrough. This is apparently in university-oriented and government-led collaborative innovation.

Collaborative innovation contains part of open innovation, the participants break organizational boundary to seek cooperation from outside, research and innovate jointly, which caused conflicts with the IP ownership exclusively. The participants of collaborative innovation have different needs, it is urgent to solve the problem how to satisfy different needs and allocate IP ownership among these participants [5]. Such as university, it pursues to explore the research deeper, but the company focuses on economic benefits. Thus it exits conflicts between university and company. Even though between universities, the conflicts exist, such as signature sequence.

Benefit is the tie that keeping the collaboration among participants. In practice, benefit conflicts are inevitable, the nature of allocation benefits reflect the judgment on knowledge value. To satisfy different needs of participants, it is necessary to make compromise during the allocation process. Thus the premise is to understand the constitution of IP benefits. Intellectual property is invisible property and is a kind of intellectual achievements. The collaborative innovation is a process of intellectual creation, so it is important to allocate the benefits attached to IP. Reasonable benefits allocation mechanism is guarantee for collaborative innovation strategy implementation. The benefits allocation is a key factor to determine the collaborative innovation success or not [6]. This problem has direct impact on technology innovation and technology transfer. Thus the reasonable benefits allocation mechanism can reduce the collaborative cost and inspire researchers to gain their own share, thus it can maintain the collaboration and promote the development of collaborative innovation center.

\section{Construct the IP Benefits Allocation Mechanisms}

This paper base on previous research and investigated data to construct collaborative innovation center operation mechanisms, it has three stages, namely beginning stage, operation stage and final stage. As this paper try to solve benefits allocation problems, thus we illustrate IP benefits allocation model in detail (Figure 1). 


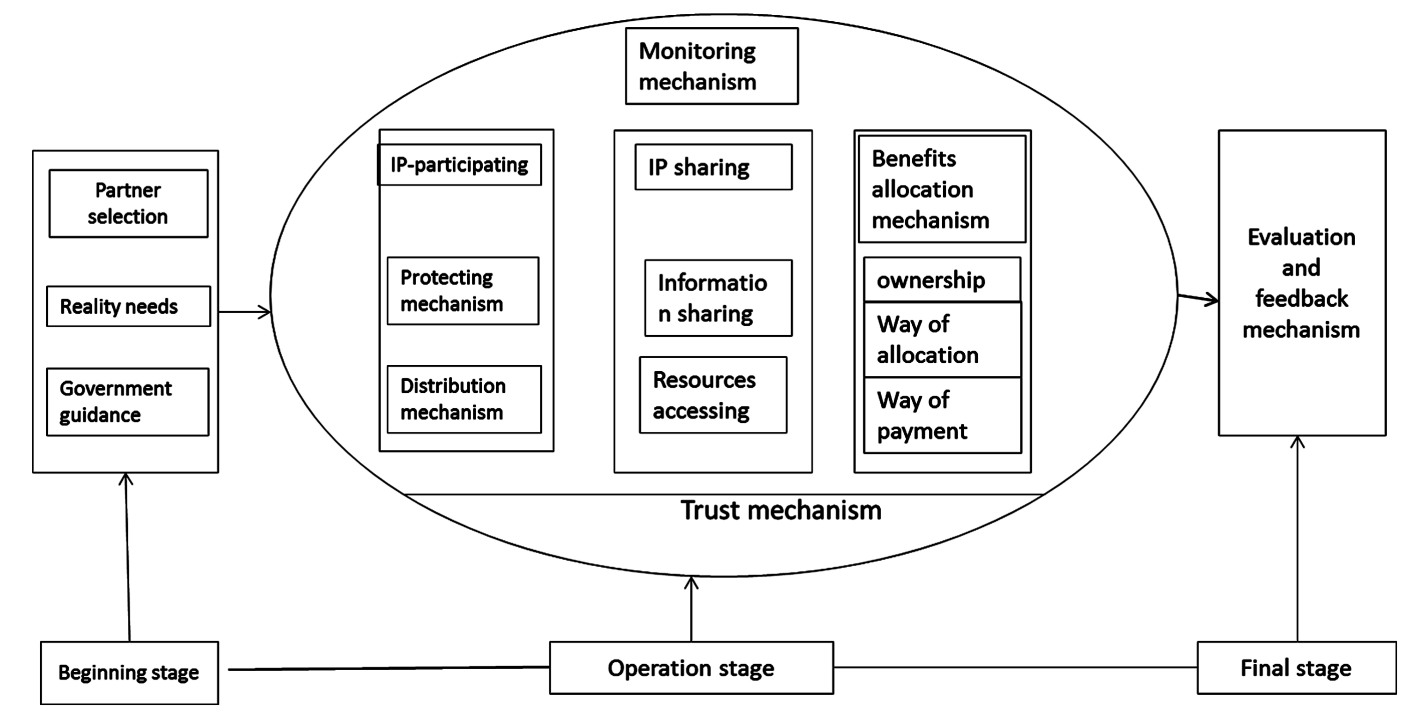

Figure 1. The IP benefits mechanism of collaborative innovation model.

\subsection{The Ownership of Intellectual Property}

If the collaborative innovation center gain some IP achievements, it is essential to ensure the IP ownership. Usually depends on different situations, for example, participants agree the IP belong to the center, this solution is relatively simple, the participants in these center can share the IP, the ownership and benefits are all belong to the collaborative center, participants can enjoy the benefits without undertaking risks. If the centers gain IP by contract with other organization, the ownership is still belong to the centers, participants can enjoy benefits as the same way. In second case, if the IP belongs to company, it could make the company more active. The company focuses on the economic benefits of IP, universities and research institutions prefer the scientific value of IP, they don't care too much about IP commercialization. Thus if the company contract with university, they can choose to have ownership, not free using right [7]. If so, the company can not only examine the researcher's achievement, but also apply IP to get protection. Finally, if participants agree the IP belongs to university, it could reduce the cost of allocation. Company could exchange intellectual property with university by investment, and the university could get licensed-IP. The company could sign contract with university based on different situations. Thus it could make IP exclusive and when the licensed IP is expired, the company could choose whether continue to select this license type or not.

\subsection{The Way of Allocating IP Benefits}

If the collaborative innovation was built jointly, company usually invest factory, machines and other equipment, the university usually use technology and participate in research work. Thus this kind of collaborative model has different participants, the way of benefits distribution that they can choose is technology transfer and shares.

1) Technology Transfer. It means the participants could transfer patent, patent application, patent licensing or non-patent technology. Technology transfer exists certain different law subjects; it usually needs transfer contract to ensure responsibility and obligation. The contracts have to be equal and fair for each participant. Also the transferor should get reasonable compensation.

2) Shares. It means converting the investment of participants into shares and evaluating the proportion. When the collaborative innovation center get economic benefits, the participants allocate benefits according to shares proportions, the invest elements are funds, factory and technology, etc. this way could protect different purposes and gain long-term benefits.

\subsection{The Way of Payment}

The existing payment methods include one-time payment, royalty-payment and dividend distribution. According different situations, participants can choose the proper method. 
1) One-Time Payment. It means that the participants get a censuses about the prize of all materials when making the contract, the prize has no relationship with economic benefits, just compensate for research institution. The participants could choose to pay all the money at one time, also could in installments [8].

2) Royalty-Payment. Transferees pay the fees to transferors by certain percentage according to sales or profits. But in practice, people usually pay a certain amount of fees first, and then pay the rest part based on sales.

3) Dividend Distribution. It means the participants get benefits according to share proportions. Participants evaluate factory, equipment, and other technology patent into shares. In this way, because every participant has certain percentage investment, it is easier to allocate the benefits in accordance with share proportion when the center gains benefits.

\subsection{Monitoring Mechanism}

Besides the benefits allocation mechanism, it is essential to build monitoring mechanism to supervisor the process of benefits allocation. The existing collaborative innovation centers have noticed that, usually they set special committee to monitor the operation of organization. But the problem is, most monitoring departments are affiliated with the central authority, if one leader has more than one position, it would lead to independence of monitoring mechanisms. In addition, to ensure the fair of benefits allocation process, the collaborative innovation center would ask the third party, such as accounting firms, to examine the allocation report and results [9].

\subsection{Trust Mechanism}

In addition monitoring mechanism, the collaborative innovation center should improve trust between each participant. This is because the participants are different types of organization and have different benefits. The trust mechanism can reduce communication cost and opportunistic behavior, also it could enhance the confidence between collaborative members, and thus it is helpful for knowledge creation and technology transfer.

\section{Case Study}

Culture-oriented collaborative innovation center mainly focus on philosophy and social science, to improve national soft power and strengthen the cultural pride through the collaboration between universities, research institutions and industries. There are two culture-oriented collaborative innovation centers in the first batch. We choose Collaborative Innovation Center of Judicial Civilization as the case to examine the theoretical model. As this kind of collaborative innovation center has detailed plan about IP collaboration, including IP Participating, sharing and benefits allocation. Compared with other centers, this kind of collaborative innovation center focuses more on mechanisms and regulations, so that it has a relatively sound system.

The Collaborative Innovation Center of Judicial Civilization was founded by China University of Political Science and Law, Jilin university and Wuhan university, it focuses on system reform to improve the innovation capability. The purpose of this center is to propel the juridical construction and enhance the voice of Chinese judicial in the contemporary world civilization, thus it could promote the internationalization of Chinese civilization and Chinese judicial.

We examine the theoretical model from the aspect of IP participating, sharing and benefits allocation. In the IP participating respect, the collaborative partners are equal and the center sets offices in every university. The center established rotating director to determine the work and draft files submitted to the center council and academic committee. The tenure of rotating director is one year, the collaborative partners by turns. Collaborative innovation needs to integrate existing resources and satisfy the task, thus the participated universities have to share resources and format flexible mechanisms. The "2011 Plan" office is the management agency for integrating resources and information sharing, the main duty includes: allocating the resources and making development plan, getting the required resources, solving the operation problems and so on. The funding is charged by the center, which allocate the money and supervise the expenditures.

In sharing respect, universities integrate resources based on collaboration plan and build resources sharing mechanisms within the school. In addition, according to the collaboration plan signed with other organizations, if the related organizations also need information or other resources, the resourcing sharing mechanisms should include all of them. Besides, the participated organization would achieve faulty sharing, such as exchanging talented professors, cultivated undergraduate students and graduate students jointly and setting united courses. The 
sharing scientific research resources include: share library and information resources, undertake task jointly, publish research results in the name of the center, and hold academic conference jointly. All faculties belong to participated organizations can apply and take part in the task, the organized conferences open to scholars inside and outside the universities. The participated universities plan to construct high standard collaborative innovation website and database to achieve sharing information resources. Other measures involve training faulty, employ faulty mutually and in the name of collaborative innovation center to operate with others.

In terms of benefits distribution, it was specifically regulated by the collaborative innovation center. As the ownership of IP, it was ruled that all IP belong to the center because of the particularity of research, but the researchers can share the benefits with the center, which gained from research achievements. As for the research workers, the center adopted way of rewards, one-off the reward for the research worker who primarily responsible for research subject, award amount based on the project level, A class level is two hundred thousand yuan, the sub-project is one hundred thousand yuan. B class level is fifty thousand yuan, C class level is 20 percent of the project funding, but less than fifty thousand yuan. If the research achievement wins the second prize and above of national award, the center awards the principal persons five hundred thousand yuan, the rests are three hundred thousand and one hundred thousand relatively according to the contributions of research workers, common workers would be awarded five thousand yuan. In other aspect, reward paper achievement based on paper grade and paper quality, monograph and patent can also get a certain degree of reward.

As for trust mechanism, the center decides that the principle person in each university should get together regularly to discuss the affaires about the center and related research problems. Thus the partners can realize each other and solve the problems timely, so that it could enhance communication and increase trust between collaborative partners. Also the center sets committees for supervisor, the expenses sheets and other documents should be reported; it also monitors the operation process in case the opportunism to protect the interests of participated partners. In addition, the center council is highest power department, decisions and documents should be passed by it. Combing with supervisor committee, these two mechanisms can secure the operation process is fairly.

\section{Advice and Suggestions}

According to our analysis for the collaborative innovation center, our paper puts forward some suggestions for perfecting these mechanisms.

1) Highlighting the Benefits Rights of Research Workers. The existing compensation way for research worker is reward. It neglects the research workers who also have share of IP [10]. Except the major project that government participates, the collaborative organization should broaden the benefits channels, such as improving salary system and reward shares, to motivate the research worker and maintain stability for collaborative innovation center.

2) Considering Second Innovation of IP. After allocating the ownership of IP, the collaborative partners still develop IP products, and apply for patents continuously. If the contract does not declare the situation, the trustee may transfer the achievements to the third party, and thus other organizations will lose the opportunity to use these research achievements. Therefore, it is necessary to pay attention to the second innovation of IP [11].

3) Perfecting the Benefits Allocation Mechanism in Collaborative Strategy. The latent premise of collaborative innovation center is that the participated organizations have common benefits. If the benefit conflicts occur, the collaborative innovation center will be collapsed. Thus, it is essential to build effective benefits allocation mechanism to promote the development of collaborative innovation center. Moreover, it is necessary to distinguish the visible and invisible benefits, and set reasonable criteria for benefits evaluation. Finally, it is vital to establish the risk-sharing mechanism and benefits balance mechanism to deal with the difficulty faced by the collaborative innovation center. It can maintain the sustainable development of the collaborative innovation centers.

\section{Acknowledgements}

This work was supported by "Research on Intellectual Property Sharing and Interests Allocating Mechanism of Collaborative Innovation Strategy" (National Soft Science Research Plan), Project Number: 2013GXS4D120. 


\section{References}

[1] Xiong, L. and Sun, Y.X. (2011) Review on Collaborative Innovation-Based on Approach Perspective. Science and Technology Management Research, 4, 49-52.

[2] Lu, R.Y., Fu, J.J. and Wang, N.X. (2003) The Nature Evolution of University-Company Collaboration and Impact on the Distribution. China Soft Science, 2, 25-28.

[3] Gloor, P.A. (2006) Swarm Creativity: Competitive Advantage through Collaborative Innovative Networks. http://dx.doi.org/10.1093/acprof:oso/9780195304121.001.0001

[4] Chen, J. and Yang, Y.J. (2012) The Theoretical Foundation of Collaborative Innovation. Science Research, 2, 54-56.

[5] He, Y.B. (2012) The Theoretical Model of Collaborative Innovation Research. Science Research, 2, 26-30.

[6] Dodgson, M. (1993) Organizational Learning: A Review of Some Literatures. Organization Studies, 14, $375-394$. http://dx.doi.org/10.1177/017084069301400303

[7] Li, W. and Dong, Y.P. (2014) The Principle of IP Ownership in Collaborative Innovation Process-From Contract to Charter. Science Research, 7, 36-38.

[8] Yang, L.L., Cai, A.H., et al. (2012) Research on IP Coordination Mechanism in Collaborative Innovation Center. Technology Development and Countermeasures, 11, 25-28.

[9] Li, L.S. (1997) Research on Benefits Allocation Mechanisms on Collaborative Innovation. China Soft Science, 2, 31 33.

[10] Fan, Y.M., et al. (2008) The Conflict and Countermeasures during the Collaborative Innovation Contract. Technology Management Research, 9, 51-53.

[11] Zhang, B. (2010) The Collaborative Innovation Model of SME. Science and Technology Management Research, 7, 4142. 